\title{
Diacronie
}

Studi di Storia Contemporanea

$\mathrm{N}^{\circ} 25,1 \mid 2016$

"Se creare è definire"

\section{Propaganda del odio y del miedo}

Una exposición anticomunista en la Francia de Vichy: Le bolchevisme contre l'Europe (1942)

\section{Antonio César Moreno Cantano}

\section{(2) OpenEdition}

Journals

\section{Edición electrónica}

URL: http://journals.openedition.org/diacronie/3903

DOI: 10.4000/diacronie.3903

ISSN: 2038-0925

\section{Editor}

Association culturelle Diacronie

\section{Referencia electrónica}

Antonio César Moreno Cantano, «Propaganda del odio y del miedo », Diacronie [En línea], № 25,

1 | 2016, documento 1, Puesto en línea el 29 marzo 2016, consultado el 30 abril 2019. URL : http:// journals.openedition.org/diacronie/3903; DOI : 10.4000/diacronie.3903 


\section{Diacronie}

N. 25 | 1|2016 "Se creare è definire"

1/

\section{Propaganda del odio y del miedo}

\section{Una exposición anticomunista en la Francia de Vichy: Le bolchevisme contre l'Europe (1942)}

\section{Antonio César MORENO CANTANO *}

Durante la Segunda Guerra Mundial se potenció en toda la Europa del Eje una serie de actos públicos que pretendían contribuir al odio de determinados grupos sociales. Bajo la estela del Tercer Reich, la Francia de Vichy desplegó por todo el país una serie de exhibiciones cuyo objetivo era vilipendiar y deshumanizar a unos colectivos concretos, como eran los judíos, los comunistas y los masones. Era el caso de exposiciones como La Franc maçonnerie dévoilèe (1940), Le Juif et la France (1941) o Le Bolchevisme contre l'Europe (1942), objeto de nuestro estudio. En este artículo profundizaremos en las técnicas empleadas en esta propaganda del odio y en los frutos literarios a los que dio lugar. Inscribiremos nuestra investigación en la Historia de las emociones, cuyos principales impulsores han sido Peter Burke, Barbara H. Rosenwein o William M. Reddy. Para ello recurriremos al odio y al miedo como ejes de nuestro discurso histórico y a la explotación que de ambos sentimientos realizaron las autoridades de la Nueva Francia para lograr el adoctrinamiento de la población hacia una determinada ideología. 


\section{Introducción: miedo y odio en el discurso historiográfico}

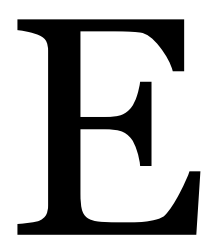

n 1978 el profesor Jean Delumeau reivindicaba el papel del miedo en la historia. En su obra, publicada en España con el título El miedo en Occidente (Siglos XIV-XVIII), recordaba «que las colectividades y emociones están embarcadas en un diálogo permanente con el miedo». El Poder ha necesitado infundir miedo y terror para sujetar, dominar y controlar a las masas ${ }^{1}$. El Estado, a través de diferentes mecanismos (de manera pasiva o violenta), puede conseguir que los ciudadanos teman a una determinada amenaza (ya sea real o imaginaria). En esta línea argumentativa se sitúa el trabajo de Corey Robin, que bajo el concepto de miedo político alude al temor de raigambre cultural y político impulsado por los gobernantes en beneficio propio, totalmente diferente de aquella respuesta instintiva, hormonal, que provoca en el ser humano un determinado elemento de la naturaleza ${ }^{2}$. El miedo puede generar, en este caso, una propensión más sencilla hacia el adoctrinamiento. Se construye con el fin de mantener a la comunidad unida frente a un «mal» o «peligro» que se presenta como algo ajeno a la misma. Esta amenaza atenta contra el bienestar de la propia población3. Es necesario cambiar nuestra percepción del pasado (no limitándonos al análisis político exclusivamente) y estudiar los sentimientos de temor, miedo o angustia sobre las formas de comportamiento. Entender cómo actitudes de rechazo, represión o marginación se explicaron o más bien se sintieron en la conciencia colectiva como una reacción ante amenazas que los intereses particulares y las tendencias políticas se encargaron de agrandar en beneficio propio4.

No sorprende, por tanto, que todos los regímenes totalitarios hayan mostrado una gran preocupación por reescribir los acontecimientos pretéritos según sus intereses, manipulándolos - en ocasiones - inyectando una carga de odio y resentimiento contra

\footnotetext{
${ }^{1}$ DELUMEAU, Jean, El miedo en Occidente (Siglos XIV-XVIII). Una ciudad sitiada, Madrid, Taurus, 1989.

2 ROBIN, Corey, Fear: The History of a Political Idea, New York, Oxford University Press, 2004, pp. 1-25.

3 Ibidem, p. 45.

4 GONZALBO AIZPURU, Pilar, STAPLES, Anne, TORRES, Valentina (eds.), Una historia de los usos del miedo, México, Universidad Iberoamericana-COLMEX, 2009, Introducción.
} 
algún grupo social o individuo determinado 5 . Y mencionamos por primera vez el término odio porque el mismo aparece como la consecuencia inevitable de la aplicación del miedo sobre la sociedad. El psicólogo Robert J. Sternberg ha sido uno de los pioneros en preguntarse sobre la naturaleza del odio e intentar explicar desde el plano científico y cultural el papel que ha desempeñado dicho sentimiento en los grandes genocidios y manifestaciones violentas de la historia, en especial en el siglo XX. Uno de los factores esenciales del odio es la "pasión», que se expresa como una intensa ira o miedo en respuesta a una amenaza ${ }^{6}$. Es fácil en ese estado anímico de miedo y odio llegar a una fase de socialización violenta, que tiene en la aterrorización personal y el adoctrinamiento violento dos de sus factores imprescindibles. El Estado se encarga de crear una imagen diabólica del otro, del adversario; y de que sus ciudadanos estén preparados para reaccionar activamente frente a este peligro (en la mayoría de ocasiones irreal)7. No se tuvo el menor reparo en la Alemania nazi o en la Francia de Vichy en crear toda una teoría racial capaz de situar en un escalón de inferioridad genética (aparte de la de índole cultural) a los judíos. Era el caso de pseudocientíficos como Adolf Bartels, Martin Staemmler, Paul Schultzer-Naumburg o Walter Gross ${ }^{8}$.

La historiografía española no ha permanecido ajena al creciente interés que han despertado estos conceptos. La Universidad de Valladolid, por ejemplo, a raíz de un ciclo de conferencias celebrado a finales de 2012 publicó los resultados de las mismas al año siguiente bajo el sugerente título, El miedo en la Historia. De la mano de un equipo multidisciplinar se analizaban las hambrunas y la sensación de desasosiego que producían en los campos de Castilla a finales de la Edad Media; el miedo a los procesos revolucionarios en Francia y España en el siglo XIX; o el pánico bursátil de Wall Street9. De igual talante era el magnífico volumen coordinado por Nancy Berthier y Vicente Sánchez Biosca, que centró sus miras en las imágenes del miedo durante la Guerra Civil a través del análisis de la propaganda visual, la prensa ilustrada, el cine...10

5 ARENDT, Hannah, Los orígenes del totalitarismo, Madrid, Alianza Editorial, 2013, pp. 464465 .

6 STERNBERG, Robert, STENBERG, Karin, The Nature of Hate, Cambridge, Cambridge University Press, 2008, pp. 62-65.

7 ATHENS, Lonnie H., The creation of dangerous violent criminals, Urbana and Chicago, University of Illinois Press, 1992, pp. 46-49.

8 KOOS, Claudia, The Nazi Conscience, Cambridge, Harvard University Press, 2003, pp. 107109.

9 BORRERO, Mercedes et al., El miedo en la Historia, Valladolid, Universidad de Valladolid, 2013.

${ }^{10}$ BERTHIER, Nancy, SÁNCHEZ-BIOSCA, Vicente (dir.), Retóricas del miedo. Imágenes de la Guerra Civil española, Madrid, Casa de Velázquez, 2012. 
Este «nuevo» ${ }^{11}$ campo de investigación, la Historia de las emociones, donde confluyen - entre otros conceptos - el miedo y el odio, ha abierto un polémico debate entre aquellas corrientes científicas que conciben las emociones como producto de un sustrato o proceso cultural (Theodore D. Kemper, entre otros) de las que las consideran únicamente la respuesta de un proceso físico (sería el caso del efecto involuntario de las hormonas ante un estímulo externo) ${ }^{12}$. En la presente investigación nos inclinamos a pensar que las experiencias mentales y corporales de la emoción traspasan el plano biológico y son más el resultado de una internalización de procesos sociales que condicionan nuestras inclinaciones y afectos ${ }^{13}$. Se trata de un camino interdisciplinar explorado en obras como las de Stuart Walton ${ }^{14}$, Barbara H. Rosenwein (Emotional Communities in the Early Middle Ages), William M. Reddy (The Making of Romantic Love) o Jan Plamper (Fear: Across the Disciplines), excelentes representantes los tres últimos del llamado giro emocional o afectivo. Este tránsito por las emociones se ha acompañado de publicaciones monotemáticas como Emotion Review y grupos de investigación tales como el Centre for the History of the Emotions, de la University of London (Queen Mary). En dicho centro se inscriben nombres como Elena Carrera o Juan Zaragoza, que tuvieron un papel destacado en el Congreso Emociones: ċun giro en historia y humanidades?, celebrado en la Casa de Velázquez de Madrid, a finales de 2013, bajo la coordinación de los profesores Juan Pro Ruiz y Stéphane Michonneau.

Buscando nuevos interrogantes - como proclamaba este encuentro - hemos elaborado este trabajo, cuestionándonos el funcionamiento y sustrato ideológico sobre el que operó la exposición Le Bolchevisme contre l'Europe (1942). La aproximación a una iniciativa de este tipo ha de servir para tender puentes desde la historia cultural a la política, con un enfoque que permite reivindicar el uso de la imagen como documento histórico y resituar la importancia que tuvieron las manifestaciones artísticas en esta

\footnotetext{
${ }^{11}$ La novedad no es tan reciente, pues ya en 1994 el neurólogo Antonio Damasio en Error de Descartes argumentaba que en la mente se dan una serie de procesos, relacionados con las señales fisiológicas de las emociones, los cuales pueden intervenir en la toma de decisiones de manera determinantes. Cfr. GÓMEZ GARRIDO, María, «Atravesar fronteras disciplinares: perspectivas estructuralistas e historicistas sobre las emociones», XI Congreso Español de Sociología, Facultad de CC. Políticas y Sociología, Universidad Complutense de Madrid, 10-12 de julio de 2013.

${ }^{12}$ Sobre este debate, del que no es nuestra intención profundizar más, véase REDDY, William M., The Navigation of Feeling. A Framework for the History of emotions, New York, Cambridge University Press, 2001, pp. 3-140.

${ }^{13}$ BOURDIE, Pierre, Miseria del mundo, Madrid, Akal, 1999.

14 WALTON, Stuart, Humanidad: una historia de emociones, Barcelona, Taurus, 2005.
} 
clase de regímenes dictatoriales como un elemento clave dentro del proceso de control social 15 .

\section{Contexto político: la nueva Francia de Pétain. Organismos de propaganda}

El día 22 de junio de 1940, el Estado francés se rendía ante el poder imparable de la Wehrmacht y firmaba un armisticio con el Tercer Reich. Al cese del combate, los dirigentes galos sumaron pronto una nueva decisión. El 25 de junio, Pétain se dirigió a sus compatriotas para anunciarles el comienzo de un nuevo orden e invitarlos a la construcción de una Francia nueva. En dicha alocución preconizó el Estado fuerte, la familia, la juventud, la jerarquía y el corporativismo, y denunciaba al liberalismo, al capitalismo y al colectivismo. Apelaba, igualmente, al espíritu de orden y de obediencia, de jerarquía social, economía controlada y organización profesional corporativa, y frente al parlamentarismo, el principio de caudillaje ${ }^{16}$.

El territorio francés, a raíz de estos sucesos, quedó dividido en dos zonas: la Ocupada (con capital en París), controlada directamente por los alemanes; y la NoOcupada (cuyo centro político era Vichy), encabezada por el mariscal Pétain. Entre sus primeras decisiones hay que destacar: se destituyó al presidente de la República; se adoptó el principio de una revisión de la Constitución; Pétain asumió las funciones de un jefe de Estado, se arrogó plenos poderes y designó a Pierre Laval como su sucesor. Ello dio lugar a una renovación nacional cuya orientación se hizo visible inmediatamente en todas sus formas: purga de la administración, prohibición de la francmasonería, castigo de los responsables de la derrota, persecución de los comunistas y de los degaullistas, desnaturalización de ciertos franceses, preparación de un Estatuto para los judíos... ${ }^{17}$ Se adoptó para el nuevo régimen el eslogan La France aux Français ${ }^{18}$.

En un primer momento, la tarea de promocionar y encumbrar la figura del nuevo chef de l'Etat correspondió al Doctor Ménétrel, persona de total confianza del mariscal

15 BURKE, Peter, Visto y no visto. El uso de la imagen como documento histórico, Barcelona, Crítica, 2001, pp. 12-16. En torno a la íntima relación entre arte y poder durante este periodo véase, Art and Power. Europe under the dictators, 1930-1945, London, Thames and Hudson, 1995, pp. 12-13.

${ }_{16}$ Sobre estas ideas véase, LACKERSTEIN, Debbie, National Regeneration in Vichy France: Ideas and Policies, 1930-1944, Burlington, Ashgate, 2012.

${ }_{17}$ BURRIN, Pierre, Francia bajo la ocupación nazi, 1940-1944, Barcelona, Ed. Paidos, 2004, p. 27.

18 TAGUIEFF, Pierre-André, KAUFMANN, Grégoire y LENOIRE, Michäel, L'antisémitisme de plume, 1940-1944. Études et documents, Paris, Berg International Editeurs, 1999, pp. 45-46. 
Pétain. En su Secretaría Particular se encuadraron diferentes departamentos encaminados a tal fin, como Información, Prensa-Radio-Censura o Propaganda del Mariscal. En el imaginario del Dr. Ménétrel, la Francia de Vichy estaba obligada a hacer frente a cuatro grandes enemigos: los comunistas, los francmasones, los judíos y a los que comulgaban con la ideología angloamericana ${ }^{19}$.

El 12 de julio de 1940 todas las cuestiones relativas a Información, Prensa y Radiodifusión fueron puestas bajo la batuta de la Présidence du Conseil, es decir, de Pierre Laval, político clave en la Francia de Vichy. La Francia de Vichy se vio obligada a convivir desde su nacimiento con el rígido control que desde París ejercían las fuerzas de ocupación alemanas. La Wehrmacht dispuso de un organizado y eficiente aparato ideológico en suelo francés, la Propaganda Abteilung, dependiente del Alto Mando alemán, en teórica conjunción con el Ministerio de Propaganda de Goebbels ${ }^{20}$.

El estamento militar germano no estuvo aislado en su tarea propagandística en Francia, más bien todo lo contrario. Junto a él interactuó el presidente de la Cámara de Comercio Franco-Alemana, el Dr. Kuntz, para asuntos de propaganda económica; el Departamento de Propaganda de las SS, encabezado por el Dr. Biderbich, a raíz de la ofensiva de 1941 contra la URSS; el representante del Ministerio de Goebbels, el mayor Schmidtke o la representación del ministro de Exteriores, Von Ribbentrop, que delegó las tareas de propaganda en el embajador y comandante militar Otto Abetz ${ }^{21}$.

Después de la dimisión forzada de Laval, favorito de los alemanes, Pétain y Darlan, nombrado vicepresidente del Consejo en febrero de 1941, tras el breve ministerio de Flandin, temen una invasión de la Francia No Ocupada e incluso la pérdida de sus colonias. Por eso Darlan refuerza la colaboración con los famosos protocolos de París, en mayo de 1941. A su vez, se produce una profunda remodelación de la propaganda. Con Darlan ascendieron al poder los tecnócratas y colaboracionistas. En la parcela informativa, Paul Marion fue nombrado Secretario General de Información en agosto de 1941. Contaba con una amplia experiencia en este campo, ya que en la década de los años 20 fue secretario de la Agit-prop en el Partido Comunista Francés (PCF) y posteriormente, en 1936, se unió al Partido Popular Francés (PPF) de Doriot, donde editó diversos diarios ${ }^{22}$. Centralizó todos los servicios y montó un aparato de

19 ROSSIGNOL, Dominique, Histoire de la propagande en France de 1940 à 1944. L'utopie Pétain, Paris, Presses Universitaries de France, 1991, pp. 11-15.

20 NOUBECOURT, Jacques, L'occupant allemand, in GERVERAU, Laurent PESCHANSKI, Denis (dir.), La propagande sous Vichy, 1940-1944, Paris, Bibliothèque de Documentation Internationale Contemporaine (BDIC), 1990, pp. 82-90.

${ }^{21}$ ROSSIGNOL, Dominique, Histoire de la propagande en France..., cit., pp. 51-52.

22 AMAURY, Philippe, Les deux premières expériences d'un «Ministère de l'information» en France, Paris, Librairie Générale de Droit et Jurisprudence, 1969, pp. 124-130. 
propaganda de Estado único en la historia de las instituciones políticas y administrativas de Francia. Concebía a Francia como una patria que no podía ser más que una, sola e indivisible. Había que excluir de la misma lo que no era específicamente nacional, es decir, los judíos, los comunistas y los gaullistas ${ }^{23}$.

El regreso de Laval como líder del Gobierno, ministro del Interior, de Exteriores y de Información, en abril de 1942, abre una nueva etapa en la configuración de la propaganda de Vichy. El secretariado de Información y Propaganda se dividió: el primero pasó a estar dirigido por Bonnefoy y el segundo por Paul Creyssel, adherido al Partido Social Francés.

El cambio ministerial de enero de 1944, impuesto por los alemanes, condujo al nombramiento del ultracolaboracionista Philippe Henriot como secretario del Estado de Información y Propaganda ${ }^{24}$. En esta última fase de la propaganda de Vichy se produjo una radicalización del mensaje a transmitir a la población. La propaganda de Vichy pretendió, a lo largo de su existencia tal y como plasmó Pierre Laborie, dar un «apoyo popular y legitimidad al régimen de Pétain», en un momento histórico trágico como fue la derrota ante Alemania; y «encuadrar a la sociedad francesa dentro de las necesidades del nuevo orden» que Hitler estaban edificando en Europa ${ }^{25}$.

\section{Exposiciones de propaganda en la Francia de Vichy: generalidades}

Junto a todos los organismos de propaganda indicados en párrafos anteriores, existieron otros - como apéndices de los mismos - de carácter monotemático que centraron sus esfuerzos en potenciar el odio sobre determinados colectivos del país. Como había expresado Paul Marion, los comunistas, los masones y los judíos eran elementos «extranjeros», ajenos al verdadero ser francés. Había que excluir a los «inasimilables et indésirables» para completar la Révolution nationale ${ }^{26}$. A esta misión se consagraron varios cuerpos estatales, que se apoyaron en una literatura y propaganda del odio y del miedo para presentar ante la sociedad unos estereotipos

${ }^{23}$ FORTI, Steven, El peso de la nación. Nicola Bombacci, Paul Marion y Óscar Pérez Solís en la Europa de entreguerras, Tesis doctoral, Universitat Autònoma de Barcelona, 2011, pp. 371-373. 24 Philippe Henriot fue un destacado orador y un católico convencido, que en los años 20 militó en la Federación Nacional Católica de Castelnau. Más adelante, desempeñó un papel activo en el diario Je suis partout y Combats, creado por la Milicia francesa en 1943. Cfr. PESCHANSKI, Denis, «Contrôler ou encadre?», cit, pp. 30-31.

25 LABORIE, Pierre, «L'evolution de l'opinion publique», in GERVERAU, Laurent, PESCHANSKI, Denis, La propagande sous Vichy..., cit., p. 227. Del mismo autor, L'opinion française sous Vichy, Paris, Éditions du Seuil, 2001 (edición revisada y ampliada).

${ }_{26}$ TAGUIEFF, Pierre-André, KAUFFMANN, Grégoire, LEONIRE, Michäel, L'antisémitisme de plume..., cit., p. 45 . 
despreciables de los «enemigos» del país, que no diferían de aquellos a los que se estaba persiguiendo y eliminando por esas épocas en el Tercer Reich. En mayo de 1942, por ejemplo, desde el Cuartel General del Führer se animaba - una vez más - a toda la Europa del Eje a «luchar contra los judíos, los franc-masones y otras ideologías [comunismo] contrarías al nacionalsocialismo»27. Para acabar con la masonería, la Francia de Vichy dispuso del Service des Sociétes Secrètes (S.S.S.), bajo el mando de Jean Marques-Rivière para la Zona Norte; el Centre d'Action et de Documentation (C.A.D.), con la presencia de Henry Coston; y el Cercle d'études historiques, politiques et sociales, presidido por Bernard Fä̈28. Contra los judíos operaron gran número de cuerpos propagandísticos. Los alemanes constituyeron en la Zona Ocupada el Institut d'Étude des Questions Juives (I.E.Q.J.), bajo la égida del miembro de las S.S., Theodore Dannecker. Por parte gala, encontramos al Commisariat Général Aux Questions Juives (C.G.Q.J.), dirigido en sus inicios por Xavier Vallat; y el Institut d'Étude des Questions Juives et Ethnoraciales, controlado por el profesor Georges Montandon'29. Finalmente, la propaganda anticomunista descansó sobre los hombros del Comité d'Action Antibolchevique (C.A.A.), en manos de Paul Chack; y su filial, el Centre d'Études Antibolcheviques (C.E.A.)30.

Fruto de la actividad de estos organismos se proyectaron exposiciones antimasónicas (La Franc-maçonnerie dévoilèe, 1940) ${ }^{31}$, antisemitas (Le Juif et la France, 1941) ${ }^{32}$, y de signo "positivo y de autopromoción», como el ciclo de La France Européenne33.

27 ROSSIGNOL, Dominique, Vichy et les Francs-maçons. La liquidation des sociéteés secretes, 1940-1944, Paris, J.C. Lattés, 1981, p. 30.

${ }^{28}$ ROSSIGNOL, Dominique, Histoire de la propagande en France..., cit., pp. 240-247.

29 JOLY, Laurent, Vichy dans la «Solution Finale». Histoire du Commisariat Général aux Questions Juives (1941-1944), Paris, Bernard Grasset, 2006.

3o LAMBERT, Pierre Philippe, LE MAREC, Gérard, Partis et mouvements de la collaboration. Paris: 1940-1942, Paris, Jacques Granches, 1993, capítulos 22 y 23.

${ }^{31}$ Cfr. PERRIN, Jean-Paul, «Jacques de Lesdain: Itineraire(s) d'un collaborateur (4ème partie : 1940-1944, sur la scene de la collaboration)», in Histoire et Collection de la Presse Illustree (XIX'̀me-XX X̀me Siecle), URL : < histpresseillustree.blog.lemonde.fr > [consultado el 26 de octubre de 2014] o el catálogo de la misma, Exposition Maçonnique au Petit-Palais, Paris, 1940. 32 Cfr. BACH, Raimond, "Identifying Jews: The Legacy of the 1941 Exhibition Le Juif et la France», Studies in $20^{\text {th }}$ Century Literature, 23, 1/1999, pp. 65-92; KASPI, André, «Le Juif et la France, une exposition à Paris en 1941", in Le Monde Juif, 79, 1975, pp. 8-20; BENZ, Wolfgang, Der Ewige Jude. Metaphern und Methoden nationalsozialistischer Propaganda, Berlin, Metropol, 2010, capítulo 15.

33 MORENO CANTANO, Antonio César, LÓPEZ ZAPICO, Misael Arturo, «Propaganda positiva en la Francia Ocupada y en el régimen de Vichy: el ciclo de exposiciones de la France Européenne», in Circunstancia, 36, 1/2015, URL:

$<$ http://www.ortegaygasset.edu/publicaciones/circunstancia/n36-enero-

2015/articulos/propaganda-positiva-francia-ocupada-regimen-vichy $>$ [Consultado el 3 de marzo de 2015]. 


\section{El Paraíso Soviético en el imaginario de Vichy: Le bolchevisme contre l'Europe (1942)}

El concepto de peligro bolchevique se extendió rápidamente por Europa tras el estallido de la Revolución Rusa en 1917. En Francia, en ese mismo año, subía al poder el Bloque Nacional. Políticos como Albert Sarraut o André Tardieu hicieron del anticomunismo una de sus señas de identidad 34 . Ya en plena época de Vichy, organismos como el Comité d'Action Bolchevique (dirigido por Paul Chack) y el Centre d'Études Antibolcheviques (bajo la supervisión de Louis-Charles Lecoq) - ambos financiados generosamente por las autoridades alemanas de Ocupación -, editaron numerosos títulos que participaron del anticomunismo impulsado desde los años veinte. Fue el caso de folletos como Le Chemin de la mort (André Chaumet); La Croisade antibolchevique (Jean Xydias); o Le Bolchevisme exploitation juive. A los mismos se incorporaron los «relatos de terror» de aquellas personas que habían logrado sobrevivir a las torturas y reclusiones en los campos de prisioneros soviéticos. Era el caso de testimonios como el de Léon Moucheboeuf y su obra Dix-huit ans en URSS 35 .

Meses antes del inicio de la exposición Le bolchevisme contre l'Europe, se constituyó una Oficina de Prensa del mismo nombre que publicó cinco folletos propagandísticos de gran difusión. La mayoría de ellos fueron firmados por periodistas y políticos muy vinculados al Parti Populaire Français (PPF) ${ }^{36}$, que formaban parte de - como los bautizó Dominique Rossignol - «les ultras de la collaboration parisienne»37.

La exposición se enmarcó en plena ofensiva de los ejércitos del Eje contra la URSS (Operación Barbarroja). El 1 de marzo de 1942, fecha en la que se puso en marcha la exposición, los soviéticos contraatacaban en Crimea, en la Península de Kerch. Pétain había iniciado a mediados de febrero el Procès de Riom, donde se acusó a Léon Blum,

\footnotetext{
34 BROCH, Ludivine, CARROL, Alison (editores), France in an Era of a Global War, 1914-1945, London, Palgrave MacMillan, 2014, p. 96.

35 Sobre este tipo de relatos, DUNDOVICH, Elena, GORI, Francesca, GUERCETTI, Emanuela, Reflections on the Gulag, Milano, Fondazione Giangiacomo Feltrinelli, 2003, pp. 228-229.

${ }_{36}$ La Paysannerie en URSS (1942), de Henri Mounier; Les Crimes du Guépéou en France (1940), de Maurice-Yvan Sicard; Condition de l'ouvrier en URSS (1942), de Émile Bougère; Le Communisme et les ouvries en France, firmado por Albert Beugras, Jules Teulade y René Mesnard; y L'influence de Moscou dans la politique intérieure et extérieure de la France, de Daniel Vauquelin y Claude Jeantet.

37 ROSSIGNOL, Dominique, «Les ultras de la collaboration parisienne», in GERVERAU, Laurent, PESCHANSKI, Denis (dir.), La propagande sous Vichy..., cit., p. 98.
} 
Edouard Daladier, Paul Reynaud o Maurice Gamelin, entre otros, de ser responsables de la derrota militar de junio de $1940^{38}$.

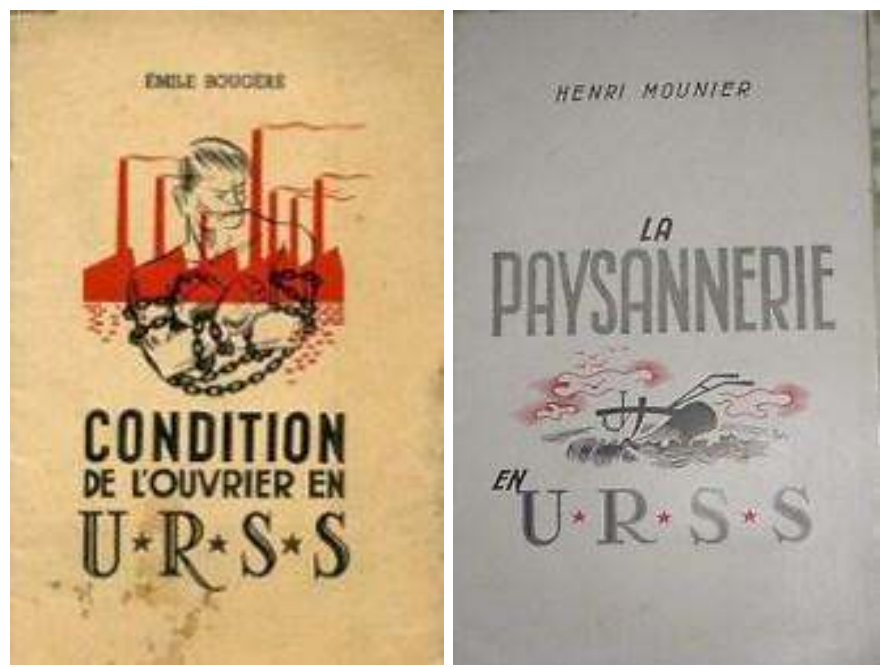

Figg. 1 y 2. Portada de algunas de las obras editadas por el Bureau de Presse de la exposición Le bolchevisme contre l'Europe.

Le bolchevisme contre l'Europe fue patrocinada por el Secretariado General de Información de Vichy, bajo la batuta de Paul Marion. Este organismo otorgó a Lecoq y Chack unos cuatro millones de francos para la organización del evento, lo que indicaba la vital importancia que recibió. Instalados en la calle de la Boetie, ambos dirigentes trabajaron mano a mano con los representantes de Alemania (Ferdinand Gerstenberg), Hungría (el corresponsal en París, François Honti), Finlandia (el cónsul general, Kaarlo Brusi), o España (el mallorquín Joan Estelrich ${ }^{39}$, impulsor de la propaganda de Francesc Cambó en Francia durante la Guerra Civil, germen de la Oficina de Prensa y Propaganda franquista en París); naciones participantes en la exposición. La gestión financiera contó con la ayuda de la Propagandastaffel, que aportó ocho millones de francos ${ }^{40}$. Lecoq y Paul Chack centralizaron la recepción de todos los proyectos, maquetas y dioramas. Entre los carteles más ilustrativos y representativos de la imagen que se quería proyectar al mundo entero se contaban los trabajos de Vica (pseudónimo de Vincent Krassousky) ${ }^{41}$, Michel Jacquot, Henri Pelletier o Serge Ivanoff.

\footnotetext{
${ }^{38}$ Sobre estos temas, BREDIN, Jean-Denis, L’infamie : le procès de Riom, Paris, Graset, 2012. 39 Un amplio repertorio bibliográfico sobre su figura y actividad pública en Actes de les jornades d'estudi sobre Joan Estelrich, Palma-Felanitx, 17-24 d'octubre de 2008, Mallorca/Barcelona, Publicacions de l'Abadia de Montserrat y Consell Insular de Mallorca, 2010, en especial pp. 83106.

40 ROSSIGNOL, Dominique, «Les ultras de la collaboration parisienne», in GERVERAU, Laurent, PESCAHNSKI, Denis (dir.), La propagande sous Vichy..., cit., p. 105.

${ }^{41}$ RAGACHE, Gilles, «Un illustré sous l'occupation : le Téméraire», in Revue d'histoire moderne et contemporaine, 47,2000 , pp. 747-767.
} 

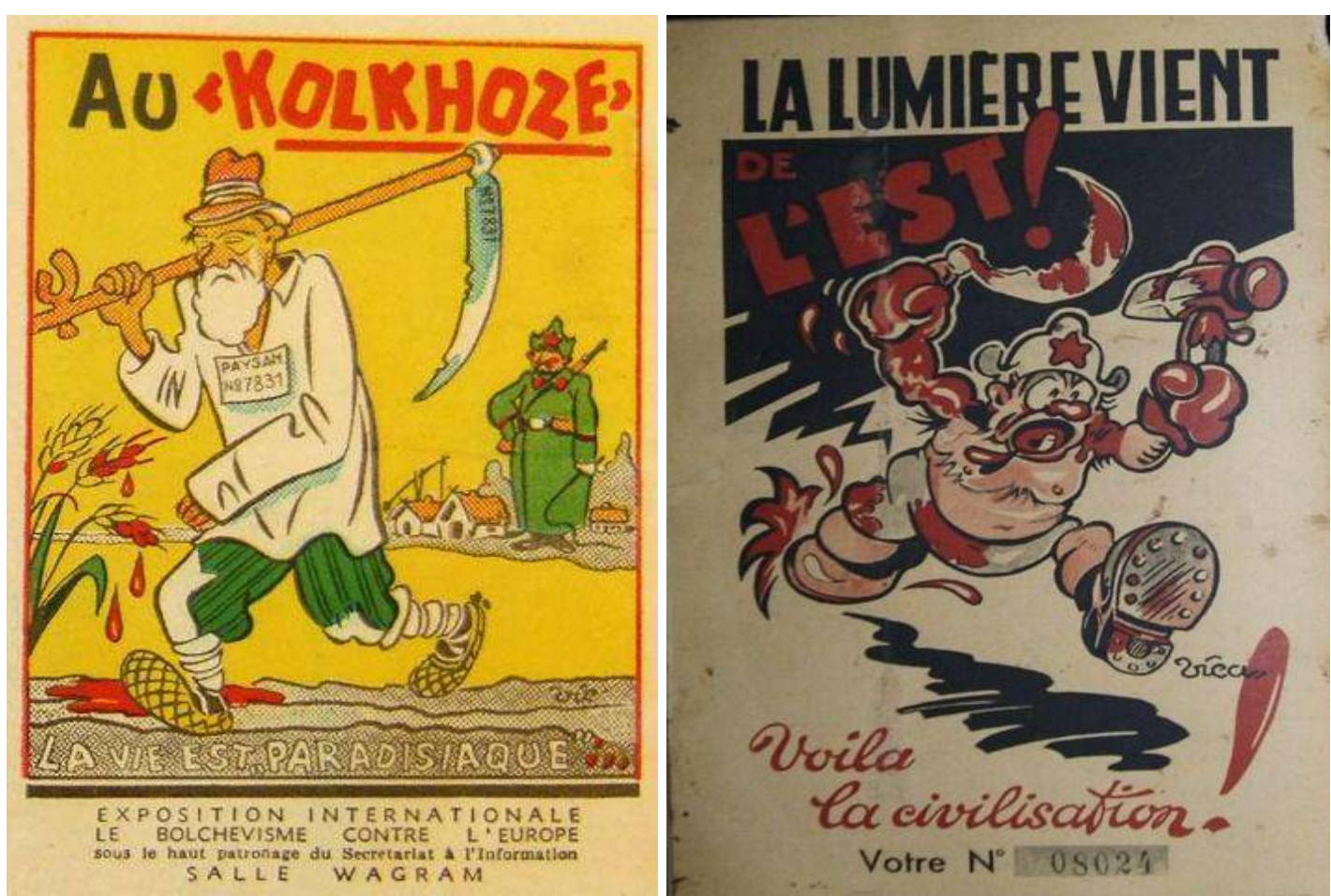

Figg. 3 y 4. Composiciones de Vica con motivo de la exposición.

Fuente: Bureau de Presse de Le bolchevisme contre l'Europe, París, 1942.

Jacquot, muy conocido por su cartel en la exposición Le Juif et la France, contribuyó con varios diseños de gran vistosidad contra la amenaza comunista, tanto en Francia como en el resto de Europa ${ }^{42}$.
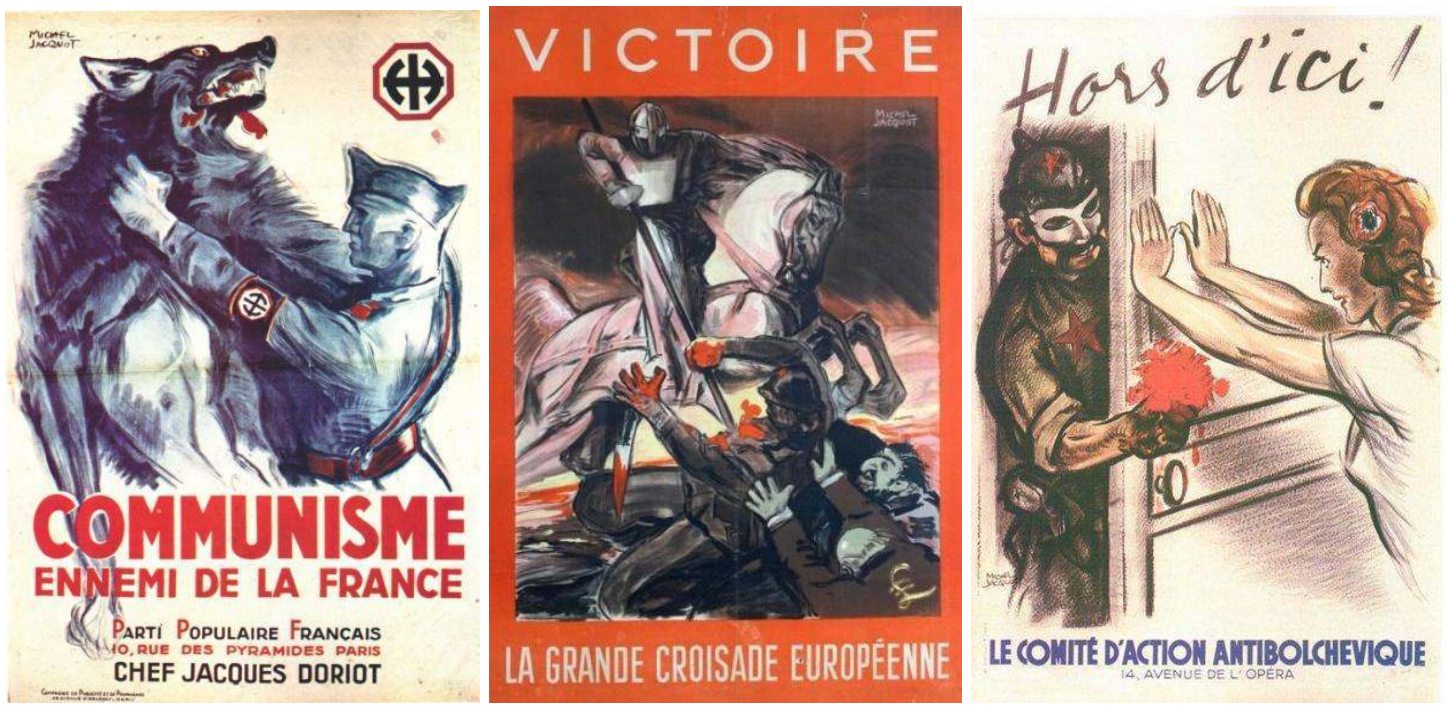

Figg. 5, 6 y 7. Composiciones de Michel Jacquot de temática anticomunista. Fuente: L'affiche antisémite en France sous l'Occupation.

42 Un estudio detallado de este tipo de composiciones en AFOUMADO, Diane, L'affiche antisémite en France sous l'Occupation, Paris, Berg International éditeurs, 2008, pp. 78-91. 
El lugar escogido para la puesta en escena de este evento fue la Salle Wagram, un teatro de París situado a pocos metros del Arco del Triunfo. El régimen de Vichy ya se había apoyado en este simbólico espacio para algunas de sus actividades como, por ejemplo, el discurso antimasónico de Bernard Faÿ en 194143. La exposición fue inaugurada, en representación del mariscal Pétain, por el embajador francés ante el Tercer Reich, Fernand de Brinon, que estuvo acompañado por una importante y relevante comitiva integrada por Paul Marion; los referidos Lecoq y Chack; además de numerosos representantes de la Alemania nazi, como el embajador Otto Abetz o el doctor Berndt, enviado del ministro de Propaganda, Josef Goebbels; junto a miembros de la diplomacia internacional, como el cónsul general de Italia, Orlandini; de Finlandia, Kaarlo Brusin; de Hungría, Charles Binder; de Rumanía, Emile Pavelesco; y de España, el cónsul Bernardo Rolland. No faltó tampoco la representación religiosa, como lo atestiguó la participación del cardenal francés Alfred Baudrillart44.

En su discurso inaugural, Brinon resaltó que esta exposición mostraba sin tapujos lo que podía suceder en Europa si no se frenaba al bolchevismo internacional. Recurría al ejemplo de España y animaba a luchar «contra los criminales que quieren acabar con la nación francesa»45. Por su parte, Marion centró sus palabras en minusvalorar «el mensaje social del comunismo ruso», apuntando hacia «la hambruna, el esclavismo y la guerra que sufrían miles de obreros en el infierno soviético» ${ }^{46}$. En el turno de Paul Chack, expresó que «nuestra exposición es, simplemente, la expresión de la verdad. Era la prueba de las condiciones de salud pública y moral» que amenazaban a Francia si no se lograba la unidad plena de los franceses47. Lecoq, seguidamente, exaltó la camaradería y el entendimiento de todas las naciones participantes frente al enemigo común: el comunismo ${ }^{48}$.

Al igual que sucedería tiempo después en Berlín, con motivo de la exposición Das Sowjetparadies, un grupo comunista de la Resistencia intentó acabar con las instalaciones de este evento mediante una bomba, que finalmente consiguió ser desactivada. Los responsables, Karl Schönhaar, Georges Tondelier y André Kirsch (miembros de los Bataillons de la Jeunesse) fueron arrestados y posteriormente fusilados. De esta noticia no se dieron mayores detalles, solo para indicar que «el

43 WILL, Barbara, Unlikely Collaboration. Gertrude Stein, Bernard Fä̈ and the Vichy Dilemma, New York, Columbia University Press, 2011, p. 180.

44 Le Petit Parisien, 2 de marzo de 1942.

45 L'Ouest-Eclair. Journal Quotidien Regional, 2 de marzo de 1942.

${ }^{6}$ Informations générales (Vichy), 80, 9 de marzo de 1942, pp. 546-547.

$47 \mathrm{Su}$ discurso, titulado «Le bolchevisme, Enterprise juive», fue publicado a posteriori en Le Cahier jaune, 4, 1942, pp. 1-2.

${ }^{48}$ Un extracto más detallado de todos estos discursos en L'Ouest-Eclair. Journal Quotidien Regional, 2 de marzo de 1942. 
Consejo de guerra alemán condena a muerte a 25 terroristas»49. Era «impensable» y peligroso dar a conocer voces contra esta política propagandística del odio50.

¿Cuál fue el plan expositivo que se utilizó? ¿Qué temas se trataron? ¿Cómo se realizó su diseño?

El visitante atravesará una larga galería que le conducirá a la sala principal. Antes de acceder a ella, se reproduce exactamente la choza de unos campesinos rusos. Posteriormente se entra en el paraíso soviético. Diferentes stands evocan la vida política, económica y social de Rusia. Esto permite comprender cómo los soviéticos, en vez de preocuparse del bienestar de su pueblo, disponen de todos sus bienes y esfuerzos para la preparación de la guerra. Otros paneles reproducen las condiciones de vida en la prisión de Riga así como las checas utilizadas en la guerra de España. En la gran sala aparecen secciones dedicadas a Alemania, Finlandia, Francia, España... Antes de salir por la calle Montenotte se atraviesa una sala de honor, llamada la sala de Montoire, con una gran imagen que evoca la entrevista histórica entre el mariscal Pétain y el Führer, símbolo de la Europa que demanda liberarse de la ideología bolchevique ${ }^{51}$.

Esta sencilla, pero clarificadora nota de prensa, resumía perfectamente el plan temático trazado para la exposición. En el exterior, antes de penetrar en la Sala Wagram, se colocó un gran panel sobre la fachada con las banderas de las naciones participantes. Estaba coronado con una réplica de la escultura «El Obrero y la Koljosiana», de Vera Moukhina, símbolo del pabellón soviético en la Exposición Internacional de París de 1937. En la larga galería que se citaba, el decorador Pelletier elaboró unas majestuosas composiciones en las que se podían visualizar a miles de figuras que, por sus rasgos y la Menorá (candelabro de aceite de siete brazos) que portaban, se identificaban rápidamente con el pueblo judío, venerando un templo presidido por la estrella comunista. Este "pueblo de autómatas», como se explicaba en el catálogo, contrastaba con la libertad de acción y prosperidad en la Francia de la Révolution Nationale. En otro de los frescos de Pelletier se consideraba al mundo bolchevique como un caos (donde solo primaban los instintos más primarios), creado por el «Dios» Karl Marx, que observaba desde el cielo el fruto de su «creación»,

49 L'Ouest-Eclair. Journal Quotidien Regional, 26 de abril de 1942.

50 OUZOLIAS, Albert, Les Bataillons de la Jeunesse Paris, Éditions sociales, 1972; KIRSCHEN, André, Le Procès de la Maison de la Chimie (7-14 avril 1942). Contribution à l'histoire des debuts de la resístanse armée en France, Paris, L'Harmattan, 2002; URL: < www.diggerjournal.net $>$ [consultado el 3 de marzo de 2015]

51 «L'exposition Le bolchevisme contre l'Europe étalera l'affreuse condition du peuple russe», in Le Petit Parisien, 21 de febrero de 1942. 
portando en sus brazos unas «Tablas de la Ley» en las que se podía leer en letras mayúsculas el nombre de Lenin y Satán.

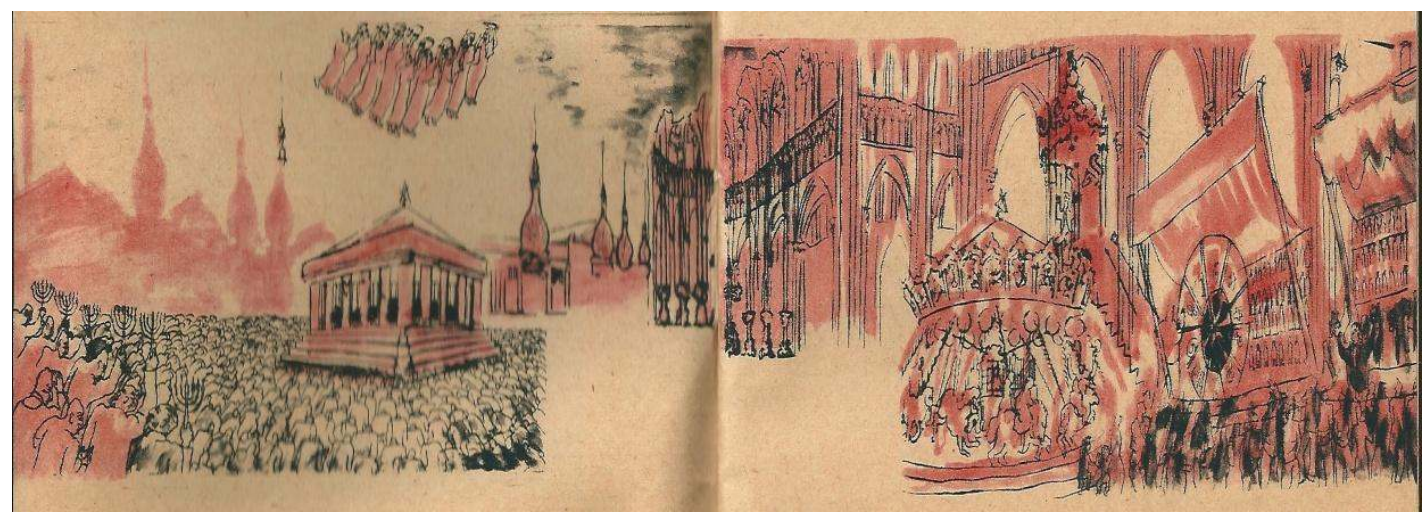

Fig. 8. Uno de los frescos de Pelletier que decoraba la galería sobre el mundo soviético Fuente: Bureau de Presse de Le bolchevisme contre l'Europe. París, 1942.

Como reproducía «Le Petit Parisien», existieron varios espacios, llenos de fotomontajes, tablas estadísticas, gráficos y otros elementos, que querían desmontar la creencia sobre el mito del paraíso soviético. En «riquezas naturales de la URSS», un amplio mapa de este país indicaba el lugar y cantidad exacta de petróleo, madera, hulla, fosfatos... que poseía el régimen de Stalin. En cada una de estas materias primas se posicionaba a la cabeza de la producción mundial. Por tanto, - como se cuestionaban en varios rótulos de la exposición -, ¿̇por qué el pueblo se veía abocado a las más crueles de la miseria? Máxime cuando la producción industrial había aumentado de manera imparable desde 1923, como se razonaba en otro panel. En «los obreros en la URSS» se analizaba el descenso de su salario y se podían contemplar imágenes de una casa soviética típica en Minsk, reflejo de la más extrema de las pobrezas. La respuesta a todas estas contradicciones era explicada gráficamente en un fotomontaje en el que se leía: «Todo para el Ejército, nada para el pueblo». 

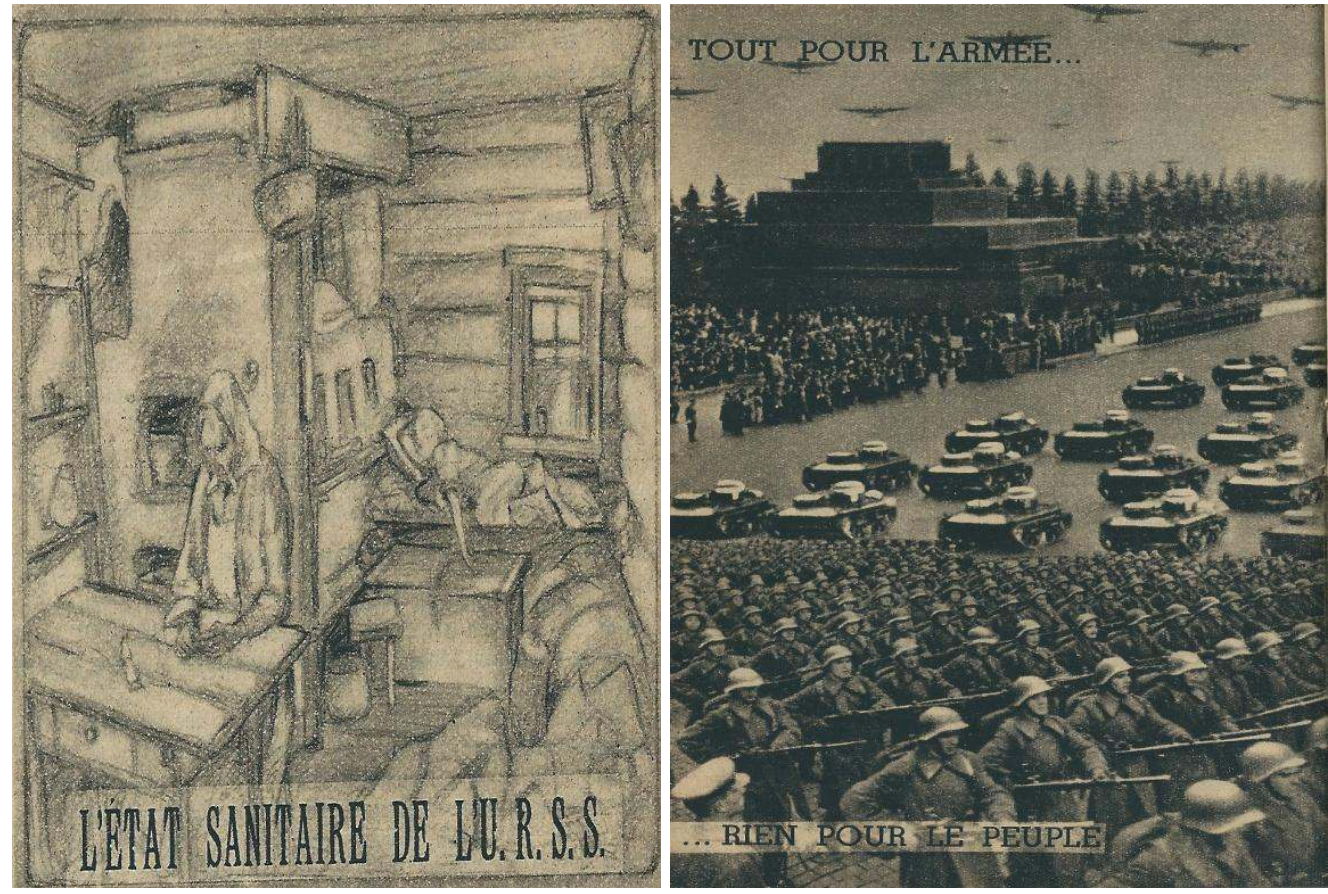

Figg. 9 y 10. Paneles de la exposición. Frente a la miseria del pueblo la opulencia del Ejército Rojo.

Fuente: Bureau de Presse de Le bolchevisme contre l'Europe, París, 1942.

Al que se oponía a esta política económica o no cumplía el ateísmo estatal sólo le esperaba el confinamiento y la muerte, como se encargaban de recordar fotografías de gran crudeza sobre los crímenes de la G.P.U.; un mapa con la localización de los principales campos de concentración rusos; o los datos que aludían - en el stand «Los Sin-Dios» - a los católicos, ortodoxos y protestantes asesinados desde la implantación del socialismo soviético. Este panorama de violencia - como recalcaban una y otra vez los responsables de la exposición - era responsabilidad del Partido Comunista, que estaba mayoritariamente en manos judías ${ }^{52}$.

Una vez atravesada esta «galería del horror», la luz y la esperanza llegaba con la sala central dedicada a las naciones de la Nueva Europa. En ellas se combinaban los magníficos paneles decorativos de Jacquot o Depuy con las imágenes de tono más sombrío sobre el peligro o presencia pasada del comunismo en estos países. Era un gran espacio circular con un gigantesco mapamundi en el centro con el continente europeo orientado a los stands de las potencias mencionadas. En cada uno de ellos se describía la particular disputa de cada uno de ellos con el bolchevismo: «Alemania en 1919 y en la presente guerra; Hungría bajo Bella Kun y sus miles de muertos; Finlandia combate aún contra el Komintern...». Y, por supuesto, España que «es de todas las

${ }_{52}^{2}$ Toda la información sobre estos paneles ha sido extraída del catálogo, Le bolchevisme contre l'Europe, París, 1942. 
naciones aquí presentes la que más ha sufrido»53. El plan expositivo del panel español fue responsabilidad del escritor y propagandista Joan Estelrich. Era, sin duda, la persona más indicada para dicha tarea por su perfecto conocimiento del país vecino y por la extensa red de contactos que había consolidado desde los años de la Guerra Civil. Personajes del más alto rango en los organismos culturales y propagandísticos de Vichy, como Bernard Faÿ (publicó un artículo en la revista Occident - dirigida por Estelrich - en 1940) o Paul Chack (uno de los firmantes del Manifiesto de los Intelectuales Franceses a favor de Franco, iniciativa del propio Estelrich) se encontraban entre su nómina de colaboradores y amistades ${ }^{54}$. Con la participación española en esta exposición se quería reclamar un papel líder a nivel internacional en la oposición al comunismo e intensificar las relaciones culturales entre Madrid y París. La prensa franquista dedicó elogiosas palabras a la participación española:

La aportación de la experiencia nacional a la exposición... constituye un índice precioso de uno de los capítulos más tremendos, complejos e instructivos de la historia contemporánea. Ni siquiera el pabellón general, o sea, el muestrario específicamente ruso, tendrá la fuerza evocadora del nuestro55.

El panel del régimen franquista explicaba al espectador francés la preparación del asalto al Poder por el comunismo (octubre de 1934); el combate en la guerra de España y «la reconstrucción de España de la guerra liberadora». Como anexos se incluían las reproducciones fidedignas de una Checa en Barcelona y un cinematógrafo donde se «proyectarán películas relativas a las atrocidades cometidas en zona roja» ${ }^{6}$. En las páginas reservadas a España en el catálogo, el cónsul Rolland escribía que «el suyo era el país antibolchevique por excelencia» 57 .

\footnotetext{
53 «A l'exposition Le bolchevisme contre l'Europe», in Moniteur Viennois 28 de marzo de 1942. 54 Sobre estas relaciones véase, MASSOT I MUNTANER, Josep, Tres escriptors davant la Guerra Civil. Georges Bernanos, Joan Estelrich y Llorenç Villalonga, Barcelona, Publicacions de l'Abadia de Montserrat, 1998, pp. 138-159; De la Guerra i de l'Exili. Mallorca, Montserrat, França, Mèxic (1936-1975), Barcelona, Publicacions de l'Abadia de Montserrat, 2000, pp. 236276.

55 «Presencia española en la Exposición titulada El bolchevismo contra Europa», in $A B C, 18$ de febrero de 1942.

${ }^{6}$ Ibidem.

${ }_{57}$ Catálogo de la exposición Le bolchevisme contre l'Europe, Paris, 1942, sin paginar.
} 


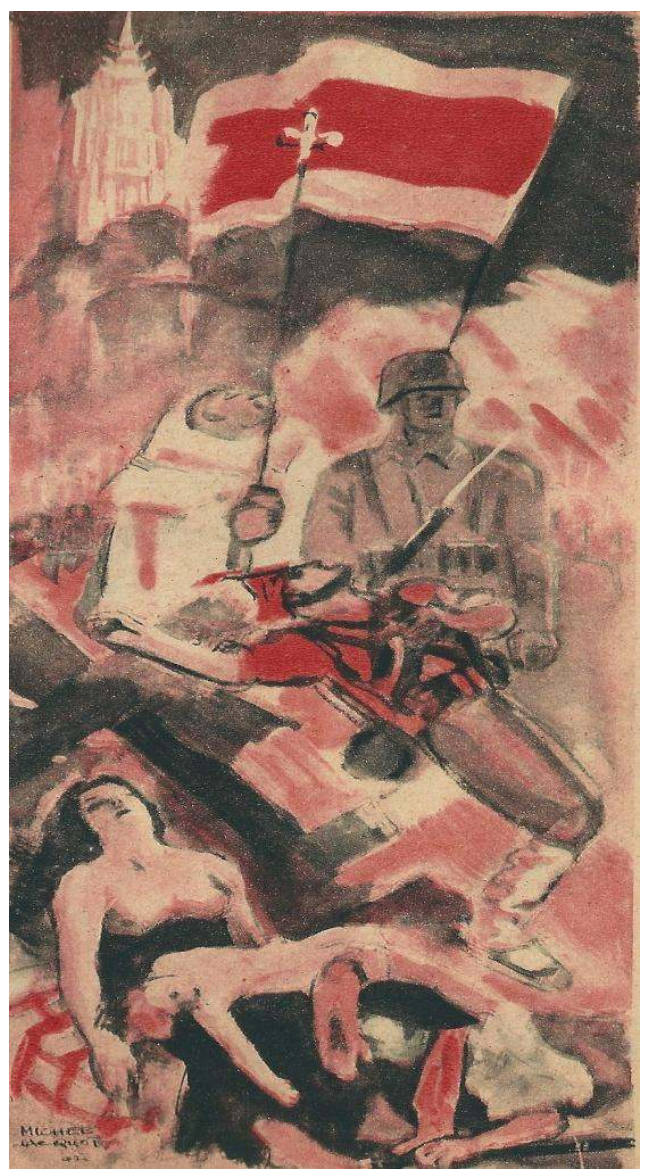

Fig. 11. Cartel de Michel Jacquot en el stand español.

Fuente: Bureau de Presse de Le bolchevisme contre l'Europe, París, 1942.

Uno de los dibujos más sobresalientes que decoró este panel fue firmado por la pluma de Jacquot. En él tenían cabida varios elementos propios de la España franquista, como el catolicismo (presencia de una catedral y de un religioso que enarbolaba una cruz); el sacrificio (cuerpos de varios civiles muertos y de un legionario desfalleciendo) y el carácter internacional del conflicto del 36, como lo ejemplificaba la presencia de un miembro de la Wehrmacht. Este juego de simbolismos estuvo muy presente en las imágenes con las que el artista francés inundó el «pabellón» germano y galo. En ambas, una figura femenina que preside el cuadro, posible personificación de la «Madre-Patria», animaba a sus «hijos» (los soldados) - incluso a los de diferentes periodos históricos, en una especie de confrontación entre el Bien y el Mal - al combate contra el enemigo. 

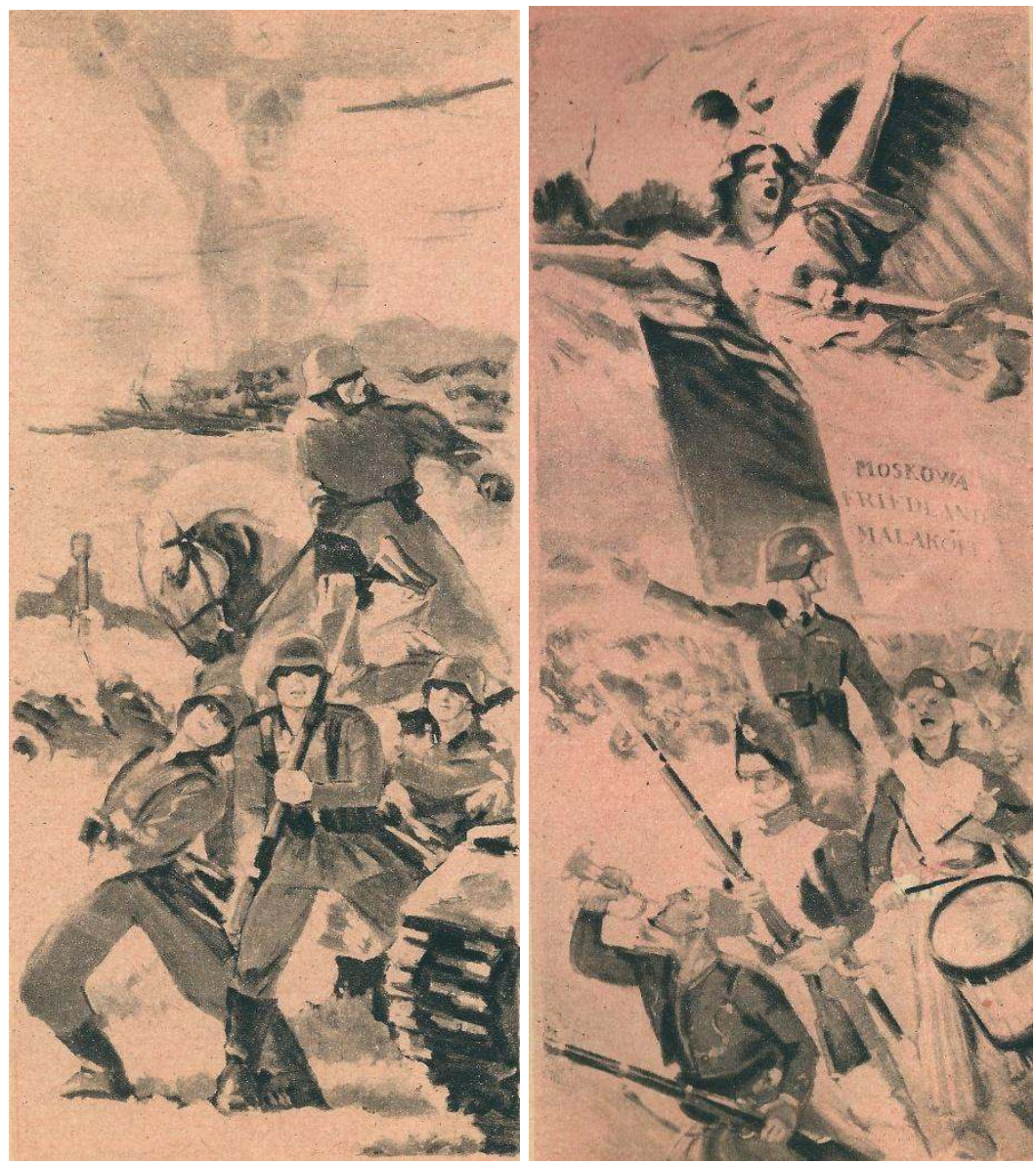

Figg. 12 y 13. Decoración del stand alemán (izquierda) y francés (derecha), obra del artista Jacquot.

Fuente: Bureau de Presse de Le bolchevisme contre l'Europe, París, 1942.

Otra creación de Jacquot, referida a la entrevista de Montoire, cerraba la exposición. Hitler y Pétain sellaban la colaboración entre Alemania y Francia sobre un fondo inundado de tumbas. Sobre las cenizas de Europa se levantaría un Nuevo Orden que requería irremediablemente de la alianza con el ocupante germano. Esta exposición, sin duda, fue uno de los frutos de este nuevo entendimiento. Meses después, y atendiendo a la temática establecida en ella, se celebraba en el corazón del Reich un nuevo acto propagandístico de odio anticomunista: Das Sowjetparadies ${ }^{58}$. Ambos eventos constituyeron un claro ejemplo de la más siniestra propaganda del odio.

${ }^{8}$ MORENO CANTANO, Antonio César, LÓPEZ ZAPICO, Misael Arturo, «La gran exposición anticomunista del Tercer Reich: Das Sowjetparadies (1942)», in Diacronie. Studi di Storia Contemporanea, 18, 2/2014, URL: < http://www.studistorici.com/wpcontent/uploads/2014/o6/16_MORENO-CANTANO_LOPEZ-ZAPICO.pdf > [Consultado el 3 de marzo de 2015]. 


\section{Conclusiones}

Ninguna imagen, y menos aún en un régimen de naturaleza fascista, está libre de intenciones, pues todas - con más razón las que han sido encargadas desde el poder conllevan cierta, o muchísima, intencionalidad política. En este tipo de Estados con pretensiones totalitarias se aspira a crear una "representación colectiva" del pasado y del presente en la que todos los miembros de la sociedad, incluyendo todos sus estratos, compartan la misma imagen sobre un suceso, personaje, idea... La ideología se dosifica y se controla a través de multitud de medios: Prensa, Literatura, Cine, Arte... Entre los más efectivos estuvieron el de la cartelística y el de la ilustración de significación política. Elementos artísticos que tomaron a todos los sectores de la población como espectadores pues la expresividad de las imágenes en ellos contenidas permitía captar de manera inmediata el emotivo mensaje que directamente enviaban a las retinas, máxime cuando operaban sobre un sustrato de ideas y estereotipos que el Estado había ido creando con anterioridad de forma sistemática y reiterativa, que se resumían básicamente en la siguiente afirmación: el odio al otro $^{59}$.

Al igual que en otros países de la Europa del Eje, la Francia de Vichy recurrió a la Propaganda y al Arte (en este caso bajo la forma de paneles e ilustraciones) para adoctrinar y encauzar a la población hacia el odio. En la exposición analizada este proceso de extrañamiento hacia el otro se dirigió contra el comunismo. Esta maniobra tuvo una doble vertiente. A nivel internacional, se quería reforzar su papel como país integrante y colaborador de la coalición (liderada por el Tercer Reich) contra el bolchevismo a raíz de la Operación Barbarroja. En el plano doméstico, reafirmando los principios del régimen de Pétain mediante el rechazo de ideas "extranjerizantes" contrarias al verdadero "ser" de Francia. Las imágenes fueron el elemento empleado para alcanzar ambos propósitos. Pero no fueron unos simples dibujos elaborados al azar o improvisados. Obedecían a un plan perfectamente orquestado, respaldado por toda una literatura anticomunista y antisemita, que años atrás ya había inoculado el virus del miedo entre la población mediante el retrato y descripción del bolchevique como un ser malvado, criminal, encarnación de todos los males... Los últimos estudios procedentes del ámbito de la Psicología explican que la memoria nos hace accesible el pasado a través del proceso del recuerdo, el cual es resultado de la activación de huellas

59 HERZ, Michael, MOLNAR, Peter (editors), The Content and Context of Hate Speech. Rethinking Regulation and Responses, Cambridge-New York, Cambridge University Press, 2012. 
de experiencias pretéritas al servicio de acciones actuales ${ }^{60}$. Pero también hay que tener en cuenta que los grupos humanos, a través del tiempo, han desarrollado procedimientos para ampliar la capacidad de mantener registros del pasado. Así surgieron sistemas de notación, poemas, historias, rituales, monumentos o exposiciones, como forma de mantener la memoria. Estos elementos hacen posible que un individuo acceda a la experiencia acumulada por el grupo. La consecuencia lógica de este proceso es la posibilidad de transformar voluntariamente la memoria natural. Un agente artificial, exterior, como el propio Estado, puede potenciar o alterar qué recuerdos del pasado son susceptibles de permanecer en el olvido o ser promocionados en el presente, como ocurrió con el tema del anticomunismo.

${ }^{60}$ RICOEUR, Paul, La memoria, la historia, el olvido, Madrid, Editorial Trotta, 2003. 


\section{* El autor}

Antonio Moreno Cantano es Doctor en Historia Contemporánea por la Universidad de Alcalá de Henares (2008). Es miembro del CEFID (Centre d'Estudis sobre les Èpoques Franquista i Democràtica) y del GREF (Grup de Recerca sobre l'Època Franquista), adscritos a la Universidad Autónoma de Barcelona; asimismo es miembro del Grupo de Investigación Catolicismo y laicismo en la España del siglo XX, vinculado a la Universidad de Alcalá, y al grupo Estudios del Tiempo Presente. Ha coordinado en Trea una trilogía sobrelas culturas bélicas y la propaganda en España entre 1936 y 1945. Su última publicación ha sido la obra colectiva Otra Iglesia. Clero disidente durante la Segunda República y la Guerra Civil, Gijon, Trea, 2015.

URL: < http://www.studistorici.com/2015/o9/24/antonio-cesar_moreno-cantano/ >

\section{Per citare questo articolo:}

MORENO CANTANO, Antonio César, «Propaganda del odio y del miedo. Una exposición anticomunista en la Francia de Vichy: Le bolchevisme contre l'Europe (1942)», Diacronie. Studi di Storia Contemporanea : "Se creare è definire", 29/03/2016,

URL:< http://www.studistorici.com/2016/03/29/cantano_numero_25/ >

Diacronie Studi di Storia Contemporanea 0 www.diacronie.it

Risorsa digitale indipendente a carattere storiografico. Uscita trimestrale. redazione.diacronie@hotmail.it

Comitato di redazione: Jacopo Bassi - Luca Bufarale - Elisa Grandi - Antonio César Moreno Cantano - Deborah Paci - Fausto Pietrancosta - Alessandro Salvador - Matteo Tomasoni - Luca Zuccolo

Diritti: gli articoli di Diacronie. Studi di Storia Contemporanea sono pubblicati sotto licenza Creative Commons 3.0. Possono essere riprodotti e modificati a patto di indicare eventuali modifiche dei contenuti, di riconoscere la paternità dell'opera e di condividerla allo stesso modo. La citazione di estratti è comunque sempre autorizzata, nei limiti previsti dalla legge. 